\title{
THEMATIC PAPER \\ The Nepal earthquake: use of a disaster to improve mental health literacy
}

\author{
D. R. Shakya
}

Additional Professor Department of Psychiatry, BPK Institute of Health Sciences (BPKIHS), Dharan, Nepal, email (BPKIHS), Dharan, Nepal, email
drdhanashakya@yahoo.com

\begin{abstract}
People were not well prepared for the psychological aftermath of the earthquake in Nepal in April 2015. A higher rate of mental disorder was noted in the ensuing months and there was a need to develop psychosocial interventions, especially for those with poor mental health literacy. Acceptable, affordable and accessible mental health awareness programmes were required. Through examples of strategies adopted by the author, this article asserts that the aftermath of natural disasters can give mental health professionals opportunities to improve mental health literacy.
\end{abstract}

\section{The earthquake}

In recent years Nepal has been subject to both natural disasters (e.g. floods, landslides, earthquakes) (Shakya, 2015) and man-made stressors (e.g. political instability, strikes, conflicts, violence) (Shakya et al, 2011). Earthquakes have hit the country every few generations; its first recorded earthquake, in 1255 , killed one-third of the population of Kathmandu Valley, including its king (National Planning Commission, 2015). The earthquake of 25 April 2015 was a major one and was followed by several para-quakes over subsequent months. Thirty-one of the country's 75 districts were affected, 14 of which were declared 'crisis hit'. The official casualty count was over 8790 casualties and 22300 injuries. Nearly one-third of the population of Nepal was affected, and almost a million houses were damaged or destroyed (Office for the Coordination of Humanitarian Affairs, 2015).

\section{Mental health in Nepal}

The prevalence of psychiatric disorder in Nepal has been reported to be as high as $35 \%$ (Upadhyaya $\&$ Pol, 2003). Despite this high prevalence, mental health remains a 'behind the scenes' issue, in the eyes of both public and policy makers. It receives little mention, insufficient funding and is never considered a priority (Shakya, 2008). People in Nepal tend not to view mental conditions as diseases, disorders or health problems, but rather as spiritual issues. This results in minimal help-seeking behaviour, which is an indicator of low levels of mental health literacy. What is most concerning is that people remain unaware of the available treatments for psychiatric disorders.

\section{Mental health effects of the earthquake}

The mental and psychological effects of the earthquake were among the least assessed, recorded, prioritised, attended and programmed areas of disaster response (National Planning Commission, 2015). Because of the low mental health literacy levels, even among social leaders and policy-makers, after the earthquake many preventable complications emerged, including higher morbidity, disability and suicide rates. The people who were already physically and mentally ill were among those most affected.

We conducted a survey among 500 direct victims of the earthquake in Bhaktapur, one of the hardest-hit districts. It revealed that almost half of the victims met criteria for 'psychiatric caseness' (Shakya, 2015). In a follow-up survey at a mental health camp, common psychiatric problems included depression, stress-related disorders, anxiety and somatoform disorders. People mainly expressed physical and somatic symptoms, although many had mood, anxiety and sleep problems and substance misuse.

\section{Post-earthquake - an opportunity for action}

In the aftermath of the earthquake, I encountered many questions from the local community about the psychological and mental (short-term and possible long-term) effects of the earthquake. I realised that this could be an opportunity to address the poor mental health literacy levels in the community because of this new interest. While the ground continued to shake (and while people's minds were shaking too), I wrote an article in a national daily newspaper within a week of the earthquake (Kantipur National Daily, 2 May 2015). I described the psychological distress that had arisen and suggested that it was so severe that people could not ignore it. Steadily the media coverage of mental health issues increased, led by the efforts of mental health professionals. This took the form of television and radio interviews, newspaper articles and lots of interest on social media. The Psychiatrists' Association of Nepal (PAN) was involved in raising awareness and this led to the Ministry of Health and Population initiating a psychosocial programme in collaboration with the World Health Organization. In my opinion, the efforts of mental health professionals were critical in the mental health effects of the earthquake being picked up by the media, noticed by the public, talked about by social leaders and heard by people in need.

\section{Improving mental health literacy - a personal journey}

The earthquake brought great loss to me personally; my house was destroyed, my community 
devastated, while many relatives and neighbours died. Amid insurmountable losses, I witnessed this disaster and cry of needy people for help. As a psychiatrist, I could empathise with the psychological distress of the victims. I decided to share my pain and suffering by writing more articles and tried to talk about the mental health consequences of the earthquake from my perspective and how using psychological strategies can help manage such problems. My articles covered causes of stress, stress-related disorders, coping and stress management, mental health symptoms, common mental disorders, depression, migraine, suicide and many other mental health issues. I printed these articles out and distributed them at local community gatherings in order to promote mental health awareness of the psychosocial effects of the earthquake and how to manage them to prevent potential complications. My book Mental Health and Mental Illness: Our Responsibility, in the Nepali language (see Bhadra, 2012), was also used as reference material and provided to schools, libraries and interested people. I was invited on many television and radio programmes to talk about psychological and mental health issues.

Many community support programmes were developed and then conducted for the public by volunteers and led by local celebrities. Many interaction programmes were conducted for public, volunteers and social leaders. Training programmes were also organised to enable volunteers and teachers to help meet the mental health need.

As a psychiatrist I was acutely aware that improving mental health awareness would in turn improve identification of issues, enable initial management strategies and allow for secondary prevention measures to be put in place. I wondered how victims could be enabled to express their inner feelings and suffering, without causing too much pain to the listener, and how best to collect information on and to analyse people's real problems and health needs. I designed a questionnaire that covered stress and health-related information, and that incorporated the General Health Questionnaire (GHQ-12) as well as the CAGE instrument on alcohol use. With the help of local volunteers (who had some health background knowledge), we managed to assess 500 earthquake victims in Bhaktapur in the survey mentioned above. Leaflets were provided to many people. Those with more serious problems were provided with further assessment and management.

\section{Conclusion}

As a Nepali psychiatrist, I know that many Nepalese people are not aware of mental and psychological changes and symptoms of psychiatric disorder. Few acknowledge mental disorder, let alone seek help. They usually attribute such problems to spiritual or other traditional influences (bad air, sorcery, ghosts etc.) and turn to traditional healers (e.g. Dhami, Jhankri). These issues are just as prevalent in the capital, Kathmandu, and other cities of Nepal, including my hometown, Bhaktapur. I had been trying to tackle these traditional beliefs for some time through the media and community awareness programmes. Such attempts had not met with much interest. However, since the earthquake, I have found people not only listening but also proactively looking for useful information and help. I heartily wish this mental health literacy movement to continue.

Through this disaster experience, what I have learned so far is that disasters, as awful as they are, can turn out to be an opportunity for mental health professionals to improve mental health literacy in our communities and sometimes across a whole country.

\section{References}

Bhadra, M. (2012) Book review. Mental Health and Mental Illness: Our Responsibility. Health Renaissance, 10, 72.

National Planning Commission (2015) Nepal Earthquake 2015: Post Disaster Need Assessment: Executive Summary. Available at http://www.npc.gov.np/en/download/major_reports (accessed 3 October 2015).

Office for the Coordination of Humanitarian Affairs (2015) Nepal: Earthquake 2015 Situation Report No. 20. Available at https:// www.humanitarianresponse.info/en/operations/nepal (accessed 3 October 2015)

Shakya, D. R. (2008) Psychiatric emergencies in Nepal. Developing Mental Health, 6, 5-7.

Shakya, D. R. (2015) Earthquake and dreaming. Developing Mental Health, 2, 6-8.

Shakya, D. R., Lamichhane, N., Shyangwa, P. M., et al (2011) Nepalese psychiatric patients with armed-conflict related stressors. Health Renaissance, 9, 67-72.

Upadhyaya, K. D. \& Pol, K. (2003) A mental health prevalence survey in two developing towns of Western region. Journal of the Nepalese Medical Association, 42, 328-330.

\section{BJPsych International's blog}

http://www.bjpinternationalblog.org

Papers on the blog:

Reflection on MRCPsych examination in the UK Viviane Ngwompo

There is no mental health without caregivers Jens Peter Dam Eckardt Jensen

Child psychiatry in Iran Hadi Shaker Naeeni

Absence of humanities in China's training of psychiatrists

Jie Li, Maosheng Ran and Cecilia Lai-Wan Chan

My first 100 private outpatients in India - the experience of a psychiatrist trained in the UK Sundararajan Rajagopal

Opportunities to improve prison mental healthcare Annie Bartlett and Gillian McGauley 